\title{
Synchronization Analysis and Implementation of Medium Term Work Plan with Annual Work Plan and School Budget Work Plan as well as Carrying Capacity on the Achievement of National Standards of Education in State High Schools in Medan City
}

\author{
Saut $^{1}$, Paningkat Siburian ${ }^{2}$, Wanapri Pangaribuan ${ }^{3}$ \\ \{kasikurpensma@gmail.com ${ }^{1}$, siburianpaningkat@unimed.ac.id ${ }^{2}$, wanapri@unimed.ac.id $\left.{ }^{3}\right\}$ \\ ${ }^{1}$ Department of Education of North Sumatera Province, Indonesia \\ ${ }^{2,3}$ Universitas Negeri Medan, Indonesia
}

\begin{abstract}
This research was carried out from 2016 to 2018, aimed at analyzing descriptively the quality of the Medium-Term Work Plan (MTWP), synchronization of the MTWP with the Annual Work Plan (AWP) and School Budget Work Plan (SBWP) formulated by 21 State High Schools in Medan City. MTWP synchronization with AWP of $62.41 \%$ and synchronization of MTWP with SBWP of $63.52 \%$; and synchronization of AWP with SBWP of $87.25 \%$. The quality of the formulated MTWP can be seen from the completeness and appropriateness of the vision, mission, goals, strategies, and milestones of 55.36\%. The carrying capacity of the MTWP towards the achievement of 8 National Education Standards is $52.31 \%$. The carrying capacity of the AWP towards the achievement of 8 National Education Standards is 50.76\%. SBWP's carrying capacity towards the achievement of 8 national education standards is $48.69 \%$.
\end{abstract}

Keywords: Synchronization, Work Plan, Capacity, National Standards.

\section{Introduction}

The issue of the quality of education in Indonesia is one of the phenomena of education that must be taken seriously by all stakeholders. The quality of education in Indonesia, in general, is still in the low category. Many students, especially state senior high school come from low economy family. They don't have much money to support the expense of them. In line with this, Muhammad stated that only about $16 \%$ of schools met the National Education Standards [1]. Pangaribuan and Aritonang report back on Muhammad Hamid's statement that national education quality maps from 2016 to 2018 have not yet reached 6 (six) grades [2]. The impact of this is that the quality of graduates is still relatively low, which is shown by the average National Examination scores and is predicted to lack global competitiveness.

The teaching-learning of many State High Schools (SHS) can not go on well. Specifically, the High School (SHS) referral to the Department of Natural Sciences (DNS) still has an average of NE scores for Indonesian language lessons 67.97; English 53,51; Mathematics 37.25; Physics 44.22; Chemistry 51,13; and Biology 48,67 [3]. Identical to that, the Social 
Sciences (IPS) department has an average national examination in Indonesian is 59.00; English 42.57; Mathematics 33.23; Economics 47.95; Sociology 51,57; Geography 49.71 [3]. Referral high school is the most qualified educational unit, but generally, it can be seen that the quality is still low, moreover the non-referral high school will get lower quality. The quality problems that have been revealed are caused by various factors which generally include teachers and educators, students, curriculum, processes, management, infrastructure, assessment, and funding. Specifically, management factors or management functions in their planning and implementation functions are analyzed in terms of synchronization and their carrying capacity towards the achievement of the National Standards of Education (NSE).

The regulation of the Minister of National Education of the Republic of Indonesia Number 19 of 2007 concerning National Education Standards for each Elementary and Secondary Education. It explains that the short-term work plan hereinafter abbreviated (MTWP) is a description of the objectives to be achieved within four years relating to the quality of graduates to be achieved and improvement of components that support the improvement of the quality of graduates by referring to eight national education standards. The annual work plan, hereinafter abbreviated (AWP), is a detailed description of the medium-term work plan of the school covering 4 (four) years as used as the basis for school/madrasah management as indicated by independence, partnership, participation, transparency, and accountability.

Whereas the work plan and school budget, hereinafter abbreviated (SBWP), is a document that contains a plan for the next year of the school development program prepared based on the school work plan to overcome the existing gap between reality and what is expected towards the fulfillment of the National Education Standards. MTWP, AWP, SBWP in each school. It becomes a very important document to determine the direction of quality education. Furthermore, the procedure for receiving fees to meet the lack of funds in the education unit originating from students' parents/guardians is carried out following applicable laws and regulations. The education unit prepares 4-MTWP, AWP, and SBWP.

The education unit compiles the SBWP which is then discussed in a committee meeting with representatives of the Parents/Guardians of Students. Education units carry out SBWP socialization to parents/guardians of students and the community. Based on the stages of the levies, it is stipulated that the levies of parents/guardians of students are only once each school year. The Education unit is obliged to free education levies for students from poor families. Granting levies may not be related to academic requirements for student acceptance, assessment of student learning outcomes, and/or graduation of students from education units. Fees by education units must be recorded/recorded and reported following statutory provisions.

The Annual Work Plan (AWP) should be derived from the Medium-Term Work Plan (MTWP), and the School Budget Work Plan (SBWP) is intended for AWP financing. The three work plans must be synchronous and must also support the achievement of the National Standards of Education (NSE). MTWP, AWP, and SBWP must be synchronously oriented and refer to NSE components. In line with this, the formulation of MTWP, AWP, and SBWP must be quality so that they are measurable and accountable. The quality of the MTWP is determined by the quality of the vision, mission, and objectives [4]. Pangaribuan added the good MTWP criteria in addition to having a vision, mission, goals, must also be planned based on the results of the SWOT analysis, having a strategy, and a program outlined in milestones [5] have a good AWP and SBWP are characterized by, (1) compiled based on mapping the condition of the education unit and vision, mission, goals; (2) the scope is minimal according to standards, (3) planning is carried out together and disseminated to stakeholders [3]. Apart from this, good AWPs must be derived from the milestones stated in the MTWP. 
A good SBWP formulation must fulfill several principles which include the principles of accuracy, detail, overall, openness (transparency), periodic, loading, flexibility. The budget plan must be careful and detailed so that it is measurable and easy to implement because of a good understanding of the budget. The budget plan must finance all educational activities in an educational unit involving 8 (eight) NSEs. Periodic principles, loading, and flexibility lead to budget planning in a limited period, such as one year, and make a school burden that must be born and provided with a variety of strategies that comply with rules and regulations, and must be flexible. In line with this, Foose stated that budgeting must be based on zero-base budgeting, which means that budgeting in the stipulated period must be balanced between income and expenditure [6]. Budgeting flexibility is defined as priority needs over time, but does not deviate from the activities that have been formulated. The principle of transparency in budgeting is interpreted as open access for stakeholders so that it can be controlled.

MTWP, AWP, and SBWP must-have carrying the capacity to achieve the National Standards of Education (NSE). The word carrying capacity is stated in the mechanical field but can also be implemented in various fields, and related to theories in the field, such as ecological theory, economic theory, sociological theory. Wen and Zhu stated that in mechanical theory, carrying capacity is defined as the ability to support mechanical loads; in ecological theory is defined as the ability to provide and maintain the availability of environmental needs to their limits; whereas in the economy it is said to be the capacity of the budget that is able to support programs and activities to achieve goals; whereas social theory is interpreted as the power of humanity in the form of systems, groups, psychology, security, and the structure of society [7].

MTWP is a very important thing because it can be used as work guidelines (terms of reference) in developing schools, can also be used as a basis for monitoring and evaluating implementation school development, as well as reference material for identifying and proposing educational resources needed for school development. With MTWP, schools can know in detail the actions that must be taken so that the goals, obligations, and targets of school development can be achieved. The MTWP also guarantees that all programs and activities undertaken to develop schools have taken into account the expectations of stakeholders and the real condition of the school. The characteristics of a good MTWP are (1) integrated, which includes the overall planning of the program to be implemented by the school, 2. Multi-year, which covers four years, (3) updated meaning that every year continues to be updated following the latest developments, (4) multi-source which indicates the amount and source of funds for each program. For example, School Operational Assistance (SOA), Regional Budget (RB), donations from the community or other sources, (5) participation arranged by the school principal, school committee and education council by involving other stakeholders, and (6) its implementation is monitored by the committee schools and other stakeholders.

Based on the definitions of various fields that have been described, it can be analyzed that carrying capacity is the ability to provide various components of the units to achieve and maintain goals to their limits. inline with this, the carrying capacity of the MTWP, AWP, and SBWP, towards the achievement of the National Education Standards is the availability of supporting components to achieve the NSE optimally. 


\section{Theoretical review}

Pikovsky, Rosenblum, and Kurths say that the term synchronization is widely used in the study of science, natural sciences, technology, and social life [8]. Balanov and colleagues say that synchronization shows the correlation of two processes [9], [10]. In line with the Balanov theory, it can be understood that synchronization is the harmony between two or more systems or subsystems or between systems and subsystems. Systems or subsystems can be in the form of work programs, activities, or budgeting. Synchronization has dynamic characteristics so that it can be seen in the harmony of the program, activities, and budgeting in its dynamics.

The synchronization of programs, activities, and budgeting emphasizes the achievement of plans that influence each other. Own activity carried out will have an impact on program achievement, if the activity is derived from the program. Own funding will have an impact on programs and activities if the financing carried out is on planned activities, and the activity is a derivative of the program.

The dynamics of budgeting will affect the dynamics of activities and also the dynamics of the program. It is said that programs, activities, and budgeting are synchronous if: (1) activities are derived from the program, and financing is carried out on the derived activities, (2) periodization of budgeting is in accordance with the periodization of programs and activities, (3) changes in budgeting will be followed by changes in performance outcomes and program. In line with this, to find the percentage of synchronization $\% \mathrm{~S}$ is the Number of Components of Annual Work Plan (NCAWP) listed as stated in the MTWP milestones divided by the number of components listed in the Medium-Term Work Plan (MTWP), multiplied by $100 \%$. This is formulated in the following equation.

$$
\% S=\frac{N C A W P}{N C M T W P} \times 100 \%
$$

Carrying capacity is the ability or capacity to provide the need to fulfill and maintain the sustainability of program implementation. The carrying capacity of the MTWP, AWP, and SBWP for the achievement of the NSE can be seen from the availability of the program which is relevant to improving the achievement of all national education standards. Carrying capacity can be calculated from the number of programs and activities listed in the MTWP, AWP, and SBWP that are relevant to the average improvement in achieving the eight national education standards.

MTWP carrying capacity towards National Education Standards (\% DD) is the number of programs and activities in the MTWP that are relevant to the eight NSEs (PGMTWP) divided by the Number of NSE Programs and Activities which are quality indicators totaling 129 indicators. The NSE indicator details are as follows: 9 content standards, 21 process standards, 7 competency standards, 19 educator and education staff standards, 28 facility and infrastructure standards, 16 management standards, standards financing of 16 indicators, and assessment standards of 13 indicators. The carrying capacity (CC) of each of the 8 NSEs are formulated in the following equations

$$
\% C C c s=\frac{C S}{9} X 100 \%
$$




$$
\begin{array}{r}
\% \text { CCps }=\frac{P S}{21} X 100 \% \\
\% \text { CCgcs }=\frac{G C S}{7} \times 100 \% \\
\% \text { CCsfeep }=\frac{\text { SFEEP }}{19} X 100 \% \\
\% \text { CCfis }=\frac{F I S}{28} X 100 \% \\
\% \text { C } m s=\frac{M S}{16} X 100 \% \\
\% \text { CC } r s=\frac{F S}{16} X 100 \%
\end{array}
$$

\section{Research method}

The population of this study was 21 state senior high schools in Medan. The samples were taken by a total sample technique, that is the whole population became the sample, so the number of samples was 21 schools, and all of them are state schools. The analysis technique used is descriptive analysis.

\section{Results and discussion}

The quality of the MTWP formulation by state senior high schools in Medan is of sufficient quality shown in Table 1 below. 
Table 1. Quality of MTWP

\begin{tabular}{cccc}
\hline No. & $\begin{array}{c}\text { Strategic Plan and the } \\
\text { Formulation Process }\end{array}$ & $\begin{array}{c}\text { School percentage which has } \\
\text { the conformity MTWP }(\%)\end{array}$ & Quality \\
\hline 1. & Vision Formulation & 100 & r $\%>75 \%=$ good \\
2. & Mission Formulation & 100 & $\begin{array}{c}\text { r } \%=50 \% \text { to } 75 \%=\text { enough; } \\
\text { r } \%=25 \% \text { to } 54 \%=\text { less; }\end{array}$ \\
3. & Formulation of Goal & 100 & \\
4. & Formulation of Strategy & 62,50 & \\
5. & Formulation of Milestones & 16,67 & bad \\
6. & SWOT analysis & 4,17 & sufficient \\
7. & The formulation of inviting & 4,17 & \\
\end{tabular}

Synchronization of MTWP with AWP of $62.41 \%$ and synchronization of MTWP with SBWP of $63.52 \%$ and synchronization of AWP with SBWP of $87.25 \%$, shown in Table 2 below.

Table 2. Synchronization matrix of program plans

\begin{tabular}{clcccc}
\hline \multirow{2}{*}{ year } & \multicolumn{3}{c}{ Item match year (\%) } \\
& & MTWP & AWP & SBWP & Synchronization \\
\hline \multirow{2}{*}{2016} & MTWP & 100 & 62.43 & 63.12 & The average synchronization of the \\
& AWP & & 100 & 87.35 & MTWP with the AWP from 2016 to 2018 \\
& SBWP & & & 100 & was 62.41\%. \\
& MTWP & 100 & 62,44 & 63,45 & Average synchronization of MTWP with \\
& AWP & & 100 & 87,32 & SBWP from 2016 to 2018 amounted to \\
& SBWP & & & 100 & 63.52\% \\
& MTWP & \multirow{2}{*}{100} & 62,37 & 63,99 & The average synchronization of AWP \\
& AWP & & 100 & 87,08 & with SBWP from 2016 to 2018 was \\
& SBWP & & & 100 & $87.25 \%$. \\
\hline
\end{tabular}

The average carrying capacity of each MTWP, AWP, and SBWP towards the achievement of eight National Education Standards from 2016 to 2018 amounted to $52.31 \%, 50.76 \%$, and $48.69 \%$, as shown in the following Table 3.

Table 3. carrying capacity of program plans for achieving the NSE

\begin{tabular}{|c|c|c|c|c|c|c|c|c|c|c|}
\hline \multirow[b]{2}{*}{ Year } & \multirow[b]{2}{*}{ Program } & \multicolumn{8}{|c|}{ Carrying Capacity towards the NSE.(\%) } & \multirow{2}{*}{$\begin{array}{c}\text { avera } \\
\text { ge }\end{array}$} \\
\hline & & Stdr 1 & Stdr 2 & Stdr 3 & Stdr 4 & Stdr 5 & Stdr 6 & Stdr 7 & Stdr 8 & \\
\hline \multirow[t]{3}{*}{2016} & MTWP & 44.44 & 52.38 & 71.43 & 36.84 & 57.14 & 56.25 & 56.25 & 46.15 & $\begin{array}{c}52.6 \\
1\end{array}$ \\
\hline & AWP & 22.22 & 52.38 & 57.14 & 36.84 & 53.57 & 56.25 & 50.00 & 46.15 & $\begin{array}{c}46.8 \\
2\end{array}$ \\
\hline & SBWP & 66.67 & 33.33 & 42.86 & 42.11 & 53.57 & 50.50 & 43.75 & 53.85 & $\begin{array}{c}48.2 \\
7\end{array}$ \\
\hline
\end{tabular}




\begin{tabular}{|c|c|c|c|c|c|c|c|c|c|c|}
\hline 2017 & MTWP & 55.56 & 47.62 & 71.43 & 31.58 & 53.57 & 56.25 & 56.25 & 46.15 & $\begin{array}{c}52.3 \\
0\end{array}$ \\
\hline \multirow{5}{*}{2018} & AWP & 55.56 & 52.38 & 42.86 & 57.90 & 53.57 & 56.25 & 62.50 & 53.85 & $\begin{array}{c}54.3 \\
6\end{array}$ \\
\hline & SBWP & 55.56 & 52.38 & 57.14 & 52.63 & 53.57 & 56.25 & 56.25 & 46.15 & $\begin{array}{c}53.7 \\
4\end{array}$ \\
\hline & MTWP & 55.56 & 42.86 & 71.43 & 36.84 & 57.14 & 56.25 & 50.00 & 46.15 & $\begin{array}{c}52.0 \\
3\end{array}$ \\
\hline & AWP & 33.33 & 61.90 & 42.86 & 47.37 & 50.00 & 62.50 & 50.00 & 61.54 & $\begin{array}{c}51.1 \\
9\end{array}$ \\
\hline & SBWP & 33.33 & 47.62 & 42.86 & 47.37 & 53.57 & 43.75 & 37.50 & 46.15 & $\begin{array}{c}44.0 \\
2\end{array}$ \\
\hline \multicolumn{11}{|c|}{ Average of carrying capacity for three years against the Eight of NSE } \\
\hline 2016 & MTWP & & & & & $52.31 \%$ & & & & \\
\hline to & AWP & & & & & $50.76 \%$ & & & & \\
\hline 2018 & SBWP & & & & & $48.69 \%$ & & & & \\
\hline
\end{tabular}

information:

Stdr $1=$ Content Standard

Stdr $2=$ Process Standard

Stdr 3 = Graduate Competency Standards

Stdr 4 = Standards for Educators and Educational Personunl

$=9$ Components

$=21$ Components

$=7$ Components

$=19$ Components

$=28$ Components

$=16$ Components

$=16$ Components

$=13$ Components

$=129$ Components

\section{Conclusions}

The quality of MTWP formulation is in the good enough category based on four good, good enough, not good, and bad categories. In line with this, the MTWP, which is still quite good, needs to be improved to be good. Although planning is often discussed by organizations but the medium-term planning of the state high school education unit in Medan is still not good. In line with this Pangaribuan said that the success of an organization in achieving its objectives depends on the planning, organizing, directing, and controlling it. These four management functions cannot be ignored by effective organizations.

MTWP synchronization with AWP since 2016 is only $62.41 \%$, which means the AWP is formulated not entirely based on MTWP. This will have an impact on unsatisfactory MTWP achievement. The same thing was also found that synchronization of the MTWP with the SBWP was only $63.52 \%$ from 2016 to 2018 , which resulted in less synchronous financing with the MTWP. AWP synchronization with SBWP of $87.25 \%$ which should be $100 \%$. This indicates that the planning function related to MTWP, AWP, and SBWP is not yet good.

The carrying capacity of MTWP, AWP, and SBWP towards National Education Standards from 2016 to 2018 are $52.31 \%, 50.76 \%$, and $48.69 \%$, respectively. This can result in the nonachievement of quality standards set by the government. Based on the findings of this study, what Hamid said and revealed was that only $16 \%$ of education units in Indonesia met the NSE, even nouns of the school's report cards reached six and the national examination results also had not achieved a score of 6 . This indicates that poor planning results in poor graduate quality. In line with this, it is unnecessary to improve the quality of planning. 
MTWP, AWP, and SBWP formulated by state senior high schools in Medan to be interpreted and improved through planning assistance by planning experts facilitated by the North Sumatra Provincial Education Office. Awareness of the importance of synchronizing the MTWP, AWP, and SBWP in the planning of SHS Programs and Activities must be increased. The carrying capacity of the MTWP, AWP, and SBWP as explained in this study is not yet in line with expectations, so a review of the formulation must be carried out so that improvements are made, especially in support of the achievement of NSE.

\section{References}

[1] M. Hamid, General Guidelines for the Quality Assurance System for Primary and Secondary Education. Jakarta: Directorate General of Primary and Secondary Education, Ministry of Education and Culture, 2017.

[2] W. Pangaribuan, "Instrumentation of School Quality Performance Based on National Education Standards and Balanced Scorecard.," 2019, p. 4.

[3] M. Hamid, "Quality Score of National Education in 2018.," 2018.

[4] M. Hamid, Guidelines for Implementing Educational Quality Assurance by Education units. Jakarta: Directorate General of Primary and Secondary Education, Ministry of Education and Culture, 2016.

[5] W. Pangaribuan, "The formulation of the Strategic Plan, Work Program, and Quality Assurance System, as well as the Formulation of Quality Instrumentation at the SLB-A Education unit in North Sumatra Province.," 2019, p. 4.

[6] R. Reune A, Board of Education's Requested 2018 Operating Budget. Maryland: Howard County Public School System, 2017.

[7] W. Kui, Report on Development of Beijing, Tianjin, and Hebei Province in 2013: Measurement of Carrying Capacity and Contribution. New York: Heidelberg, 2015.

[8] A. Pikovsky, Synchronization A Universal Concept in Nonlinear Sciences. New York: Cambridge University Press, 2001.

[9] B. Alexander, Synchronization from Simple to Complex. Berlin: Springer-Verlag Berlin Heidelberg, 2009.

[10] P. Antonio, Economic Cycles in Emerging and Advanced Countries: Synchronizations, International Spillovers and the Decoupling Hypothesis. Switzerland: Springer International Publishing Switzerland, 2015. 